\title{
Robotic versus transanal total mesorectal excision in sexual, anorectal, and urinary function: a multicenter, prospective, observational study
}

\author{
Julia-Kristin Grass ${ }^{1}$ (C) Roberto Persiani ${ }^{2} \cdot$ Flavio Tirelli $^{2}$. Chien-Chih Chen ${ }^{3,4} \cdot$ Marco Caricato $^{5}$ - Alice Pecorino ${ }^{5}$. \\ Isabelle J. Lang ${ }^{1}$ - Marius Kemper ${ }^{1}$. Jakob R. Izbicki ${ }^{1}$ - Nathaniel Melling ${ }^{1}$ - Daniel Perez ${ }^{1}$
}

Accepted: 11 September 2021 / Published online: 18 September 2021

(c) The Author(s) 2021

\begin{abstract}
Purpose Improved long-term survival after low anterior resection (LAR) for rectal cancer highlights the importance of functional outcome. Urogenital and anorectal dysfunction is frequently reported after conventional LAR. Advanced minimally invasive techniques such as robotic (RoTME) and transanal total mesorectal excision (TaTME) might improve functional results by precisely dissecting and preserving autonomic nerves. We compared functional outcomes after RoTME or TaTME in a multicenter study.

Methods One hundred twenty patients (55 RoTME/65 TaTME) were prospectively included in four participating centers. Anorectal (Wexner and low anterior resection syndrome (LARS) Score), urinary (International Consultation on Incontinence-Male/Female Lower Urinary Tract Symptoms Score (ICIQ-MLUTS/ICIQ-FLUTS) and International Prostate Symptom Scale (IPSS)), and sexual (International Index of Erectile Function (IIEF), Female Sexual Function Index (FSFI)) outcomes at 12 months after surgery were compared to preoperative scores. The response rate to the 1-year postoperative functional assessment by questionnaire was $79.5 \%$.

Results RoTME enabled better anorectal function compared to TaTME (LARS score $4.3 \pm 2.2$ vs. 9.8 $\pm 1.5, p=0.038$, respectively). TaTME proved superior at preserving male urinary function, while female urinary function was comparable in both groups, with only mild postoperative impairment (RoTME vs. TaTME, respectively: ICIQ-MLUTS $13.8 \pm 4.9$ vs. $1.8 \pm 5.8$, $\mathrm{p}=0.038$; ICIQ-FLUTS Incontinence Score $-0.3 \pm 1.0$ vs. $-0.2 \pm 0.9, \mathrm{p}=0.844)$. Both techniques demonstrated comparable male (RoTME $-13.4 \pm 2.7$ vs. TaTME $-11.7 \pm 3.4, \mathrm{p}=0.615$ ) and female (RoTME $5.2 \pm 4.6$ vs. TaTME $10.5 \pm 6.4$, $\mathrm{p}=0.254$ ) sexual function.

Conclusion After adjustment for risk factors, RoTME provided better anorectal functional results, whereas TaTME was better at preserving male urinary function. Overall, both techniques demonstrated only mild postoperative functional impairment.
\end{abstract}

Keywords Functional outcome $\cdot$ Low anterior resection syndrome $\cdot$ Robotic total mesorectal excision $\cdot$ Transanal total mesorectal excision · Urogenital function

\section{Introduction}

Nathaniel Melling and Daniel Perez equally contributed in this work.

Julia-Kristin Grass

j.grass@uke.de

1 Department of General, Visceral and Thoracic Surgery, University Medical Centre of Hamburg-Eppendorf, Martinistraße 52, 20246 Hamburg, Germany

2 Fondazione Policlinico Universitario A. Gemelli IRCCS, Università Cattolica del Sacro Cuore, Rome, Italy
Over the past three decades, curative treatment of rectal cancer has led to a distinct increase in long-term survival. In addition to earlier diagnosis and more efficient

3 Department of Surgery, Koo Foundation Sun Yat-Sen Cancer Center, Taipei, Taiwan

4 College of Medicine, National Yang-Ming University, Taipei, Taiwan

5 Colorectal Surgery Unit, Università Campus Bio-Medico, Rome, Italy 
chemoradiation regimes, the introduction of total mesorectal excision (TME) has revolutionized patient outcomes [1, 2]. Sharp dissection of the mesorectal plane enables high rates of negative circumferential and distal resection margins, while precise TME can preserve the autonomic pelvic nerves [3, 4], since these remain outside the dissection plane. As a result, TME has lowered recurrence rates to 5.9\% [5], enabling a higher rate of sphincter-preserving procedures [6] and reducing urogenital and fecal dysfunction $[4,7,8]$.

However, a substantial subset of rectal cancer patients still suffers from functional impairment after curative rectal resection. Between 40 and $52 \%$ of patients state daily bowel dysfunction $[9,10]$, while one-third of patients develop a long-term urinary dysfunction, shown to be mainly associated with neural damage during surgery [11]. Sexual dysfunction is a multifactorial problem affected by biopsychological and physical factors $[4,12]$.

Several scores based on patient-reported outcomes measures (PROM) have been established to evaluate and compare functional outcomes. PROMs reflect personal impairment and provide valuable information on the quality of surgery [13]. During the postoperative course, urogenital and anorectal functions decrease to their lowest levels one month after pelvic surgery and recover to stable values after 12 months $[9,14,15]$.

Despite several well-known advantages of laparoscopic surgery regarding patient perioperative outcomes and quality of life (QoL), laparoscopic TME (LaTME) has not improved urogenital and anorectal outcomes. Indeed, LaTME has been associated with worse $[16,17]$ or similar $[18,19]$ functional results compared to the open approach (OTME). Other advanced minimally invasive techniques, such as robotic (RoTME) or transanal TME (TaTME), can help to master the limitations of conventional laparoscopic rectal resection. Thus, the question arises whether these techniques can also aid in preserving anorectal and urogenital function.

Currently, to the best of our knowledge, no direct comparison of functional outcomes between TaTME and RoTME exists. Thus, our prospective, multicenter, observational study aimed to elucidate which of these two novel techniques would enable better sexual, anorectal, and urinary function.

\section{Material and methods}

\section{Patient selection}

All patients undergoing surgery for primary rectal cancer within $15 \mathrm{~cm}$ of the anal verge, either by RoTME or TaTME, between January 2014 and February 2018, were screened for inclusion at the participating institutions. Exclusion criteria were conversion to OTME, other major surgery, disseminated disease, or death in the follow-up period. All eligible patients were invited for participation. The experimental protocol was approved by the responsible review board of the general medical council Hamburg (PV5591). All patients gave their written and signed informed consent to participate in the study.

Clinicopathological and demographic parameters and short-term oncologic outcomes were analyzed. Rectal adenocarcinoma was staged according to the 8th edition of the AJCC staging manual [20]. Adequate local staging was performed by pelvic magnetic resonance imaging (MRI) and/or endorectal ultrasound. In the case of indication for neoadjuvant treatment, patients received long-course chemoradiation with 50.4 Gy and systemic fluorouracil-based chemotherapy. Patients underwent surgery 6-12 weeks after neoadjuvant treatment. A major complication was defined as necessity for further medical or surgical intervention (Clavien Dindo III-IV, invasive treatment) [21]. Anastomotic leakage was defined by any dehiscence at anastomotic site independent of clinical manifestation [22].

\section{Functional assessment}

Validated questionnaires in the respective national language were applied to score the anorectal, urinary, and sexual function at 12 months postoperatively (which is when a stable level of function has been shown to be achieved [9, $14,15])$. Protective ileostomies, if created, were reversed at least 16 weeks before postoperative assessment. These scores were compared to preoperative values collected at time of diagnosis. Questionnaires were sent to the patients or distributed before regular appointments.

Wexner and LARS scores were used to assess fecal function [23, 24]. Patients without a sphincter-preserving procedure were excluded from this analysis. The Wexner score consists of five items and queries continence for solid and liquid stools, as well as gas, the usage of pads, and lifestyle alterations. The maximum score value is 42 , representing complete incontinence. The LARS score was developed to evaluate the severity of low anterior resection syndrome (LARS) and includes control of flatus and liquid stool and bowel frequency, as well as clustering of stools and urgency. Patients are summarized in three groups according to their score: no LARS (0-20), minor LARS (21-29), and major LARS (30-42).

Urinary function was evaluated using the International Consultation on Incontinence-Male/Female Lower Urinary Tract Symptoms Score Long Form (ICIQ-MLUTS/FLUTS LF) [25]. The scores are composed of 23 items on male and 18 items on female urinary function, followed by a scale of personal bother measured with a visual analogue scale from 0 to 10. Personal bother scores are not included in the total score, where a higher score indicates more severe urinary dysfunction. Additionally, the International Prostate 
Symptom Score (IPSS), applied to male and female urinary dysfunction in the literature, was calculated for both genders and evaluated separately [26]. It consists of seven items, yielding a maximum score of 35 points for maximal urinary dysfunction.

Sexual function was analyzed by the International Index of Erectile Function (IIEF) [27] and the Female Sexual Function Index (FSFI) [28]. These self-administered questionnaires are composed of 15 and 19 items, respectively. They query erectile and orgasmic function, sexual desire, intercourse, and overall satisfaction for male patients, and desire, arousal, lubrication, orgasm, satisfaction, and pain for female patients. Higher score values indicate better sexual function.

\section{Surgery}

The participating surgeons had already completed their learning curves of at least 40 cases for either RoTME or TaTME before the start of patient recruitment for this study. One surgeon per site met the inclusion criteria. The surgical procedures have been described previously [29]. In brief, RoTME was performed as a complete robotic procedure using the da Vinci ${ }^{\circledR}$ Surgical System (Intuitive Surgical, Sunnyvale, CA, USA). After dissection of the inferior mesenteric vein (IMV), the splenic flexure and the descending hemicolon were mobilized. Then, the inferior mesenteric artery (IMA) was dissected as a high tie. The pelvic TME was performed by dissecting the mesorectal fascia with
Fig. 1 Flowchart of the study populations. Numbers in parentheses indicate female and male patient numbers. OTME, open total mesorectal excision; RoTME, robotic total mesorectal excision; TaTME, transanal total mesorectal excision

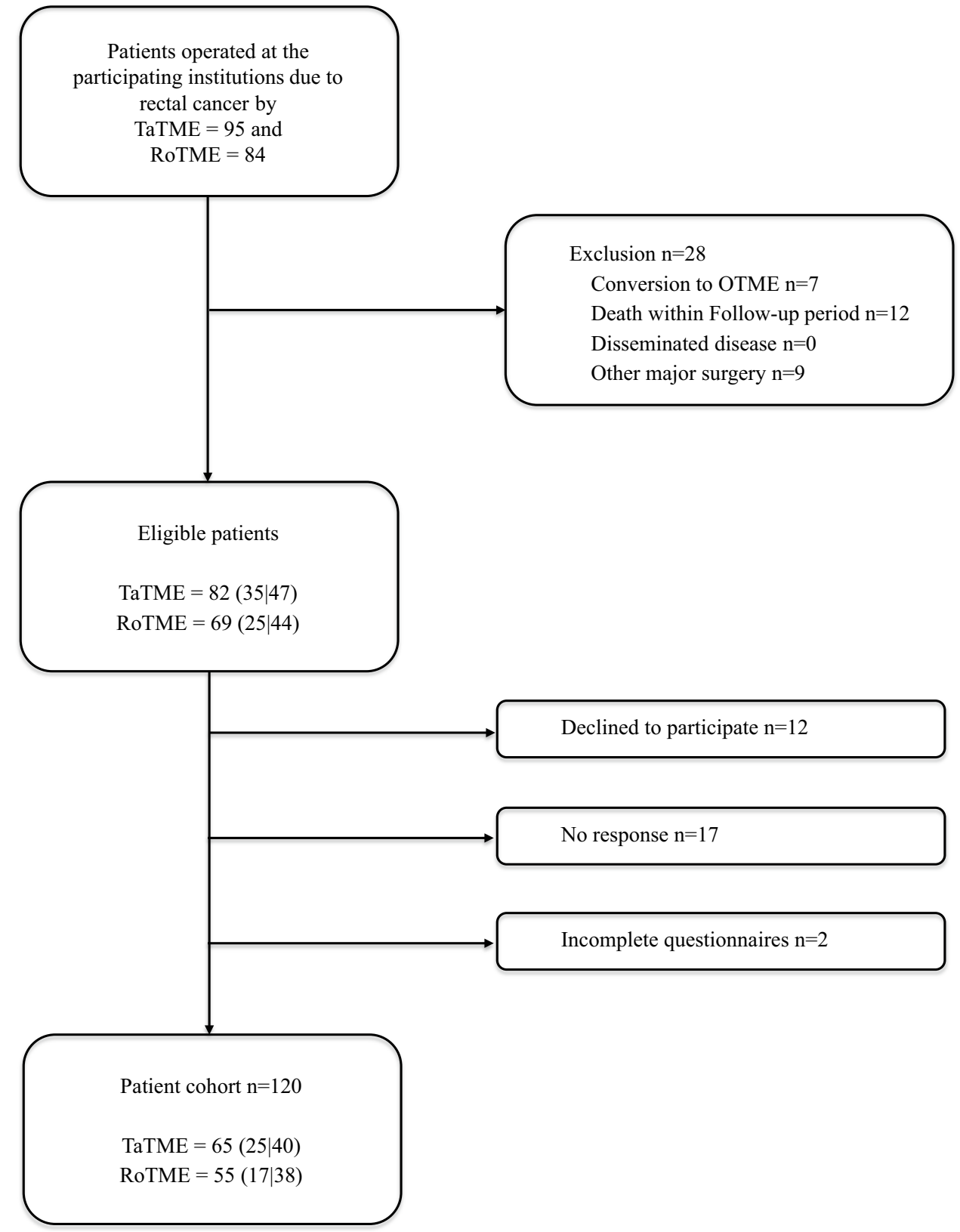


identification and preservation of the hypogastric nerves. After transection of the rectum distally of the tumor, the specimen was extracted through a Pfannenstiel incision. TaTME was conducted in a one-team approach in lithotomy position. The abdominal part was conducted as described for the robotic procedure. The TME was conducted up to the level of S3, where the abdominal part was stopped. The transanal approach was started with a purse-string closure of the rectum and insertion of the transanal port. The circular dissection was performed from caudal to cranial connecting the two dissection planes. The specimen was extracted either transanally or via Pfannenstiel.

All anastomoses were performed using a CEEA stapler as side-to-end or end-to-end stapler anastomosis.

\section{Statistics}

All statistical analyses were performed using SPSS version 23 (IBM Corp., Armonk, N.Y., USA). A two-sided p-value of $<0.05$ was considered statistically significant. Student's T-test was used for continuous variables and $\chi^{2}$-test for categorical variables. Analyses of pre- and postoperative values were performed with the Wilcoxon test for continuous and categorical variables and McNemar's test for dichotomous variables.

Traditional covariate adjusted linear models, considered as statistically equivalent to propensity score matching without the bias of observation loss due to exclusion of cases, were used to compare post-treatment change of anorectal and urogenital function between both groups. Anorectal scores have been adjusted for preoperative scores (baseline), body mass index (BMI), gender, tumor height, and radiotherapy. Urogenital scores have been adjusted for preoperative scores, BMI, tumor height, radiotherapy, and restorative surgery.

\section{Results}

\section{Clinicopathological and short-term outcomes}

One hundred twenty consecutive patients (55 RoTME and 65 TaTME) from four centers were included in the study. The overall response rate was $79.5 \%: 70.0 \%$ for female and $85.7 \%$ for male patients (Fig. 1). Thirty-eight (69.1\%)
Table 1 Patient characteristics and pathological data

\begin{tabular}{|c|c|c|c|}
\hline & $\operatorname{RoTME}(\mathrm{n}=55)$ & TaTME $(n=65)$ & $\mathrm{p}$ value \\
\hline \multicolumn{4}{|l|}{ Gender } \\
\hline Male & $38(69.1)$ & $40(61.5)$ & 0.387 \\
\hline Female & $17(30.9)$ & $25(38.5)$ & \\
\hline Age (years) & $59.2 \pm 11.9$ & $66.6 \pm 10.4$ & $<0.001$ \\
\hline \multicolumn{4}{|l|}{ Center } \\
\hline Hamburg & $41(74.5)$ & $0(0.0)$ & \\
\hline Rome Campus Biomedico & $0(0.0)$ & $15(23.1)$ & \\
\hline Taiwan & $14(25.5)$ & $1(1.5)$ & \\
\hline Rome Gemelli & $0(0.0)$ & $49(75.4)$ & \\
\hline BMI $\left(\mathrm{kg} / \mathrm{m}^{2}\right)$ & $27.2 \pm 5.3$ & $25.4 \pm 4.0$ & 0.381 \\
\hline Previous abdominal surgery & $6(10.9)$ & $15(23.1)$ & 0.080 \\
\hline Tumor localization (cm) & $6.7 \pm 5.3$ & $5.5 \pm 2.4$ & 0.116 \\
\hline Neoadjuvant radiochemotherapy & $18(32.7)$ & $41(63.1)$ & 0.001 \\
\hline \multicolumn{4}{|l|}{ Tumor stage } \\
\hline урт0 & $6(10.9)$ & $15(23.1)$ & 0.182 \\
\hline pT1 & $13(23.6)$ & $10(15.4)$ & \\
\hline pT2 & $18(32.7)$ & $15(23.1)$ & \\
\hline pT3 & $18(32.7)$ & $25(38.5)$ & \\
\hline \multicolumn{4}{|l|}{ Nodal stage } \\
\hline pNO & $35(63.6)$ & $62(95.4)$ & $<0.001$ \\
\hline pN1 & $17(30.9)$ & $2(3.1)$ & \\
\hline $\mathrm{pN} 2$ & $2(3.6)$ & $1(1.5)$ & \\
\hline LN positive (n) & $0.8 \pm 1.3$ & $0.6 \pm 2.2$ & 0.519 \\
\hline LN harvested (n) & $16.1 \pm 7.9$ & $14.2 \pm 5.6$ & 0.107 \\
\hline
\end{tabular}

Numbers indicated as absolute numbers and percentage or mean \pm standard deviation; $p$-values in bold indicate statistically significant differences between surgical techniques

$B M I$ body mass index, $L N$ lymph nodes, $n$ number, $p$ p-value, RoTME robotic total mesorectal excision, TaTME transanal total mesorectal excision 
RoTME and 40 (61.5\%) TaTME patients were male, and the mean age was $59.2 \pm 11.9$ years in the RoTME cohort and $66.6 \pm 10.4$ years in the TaTME cohort (Table 1). While there were no significant gender distribution differences, the mean age differed significantly between groups $(\mathrm{p}<0.001)$. There was no significant difference in BMI $(27.2 \pm 5.3 \mathrm{~kg} /$ $\mathrm{m}^{2}$ vs. $25.4 \pm 4.0 \mathrm{~kg} / \mathrm{m}^{2}, \mathrm{p}=0.381$ ) or tumor localization $(6.7 \pm 5.3$ vs. $5.5 \pm 2.4, \mathrm{p}=0.116)$ between the RoTME and TaTME groups, respectively, whereas neoadjuvant chemoradiation was significantly more frequent in TaTME patients ( $32.7 \%$ vs. $63.1 \%, p=0.001$ ). The tumor stage was comparable, with pT2-3 stages in most cases $(\mathrm{p}=0.182)$. In contrast, nodal positivity was higher in the RoTME group (pN1 17 $(30.9 \%)$ vs. $2(3.1 \%), p<0.001)$. No difference was found in the amount of harvested lymph nodes $(\mathrm{p}=0.107)$.

The operative time was shorter for RoTME compared to TaTME $(247.0 \pm 88.0 \mathrm{~min}$ vs. $297.8 \pm 85.0 \mathrm{~min}, \mathrm{p}=0.001)$ (Table 2). All patients in the TaTME and $87.3 \%$ in the RoTME group underwent sphincter-preserving procedures. Protective ileostomies were formed in $70.8 \%$ of restorative RoTME and in $100.0 \%$ of TaTME procedures. While minor complications occurred more frequently after TaTME $(14.5 \%$ vs. $32.3 \%, p=0.024)$, major complications were significantly more frequent following RoTME than TaTME (9.1\% vs. $0.0 \%$, respectively, $p=0.013)$, but no significant difference was found for the frequency of anastomotic leakage ( $8.3 \%$ vs. $1.5 \%, p=0.117)$. Resection margin was positive in one RoTME case, with involvement of the circumferential margin (1.8\%); however, this did not reach statistical significance $(p=0.275)$. Aboral and circumferential margins were greater after RoTME compared to TaTME $(\mathrm{p}<0.001)$. Both groups showed comparable quality of mesorectal excision $(p=0.333)$, as well as similar length of hospital stay $(p=0.166)$, readmission rates $(p=0.109)$, and follow-up time $(25.9 \pm 13.1$ vs. $25.7 \pm 11.7, \mathrm{p}=0.804)$.

\section{Anorectal function}

RoTME patients revealed no significant change in the LARS score $(p=0.630)$. Comparison of pre- and postoperative scores showed that TaTME led to a highly significant decline in fecal function (Wexner score, $\mathrm{p}<0.001$; LARS score, $\mathrm{p}<0.001$ ), but the actual impairment was mild: the mean Wexner score remained in the lower quarter postoperatively (Fig. 2). After adjustment for potential confounders, Wexner scores revealed no significant difference (Table 3, $p=0.095$ ),

Table 2 Surgical data

\begin{tabular}{|c|c|c|c|}
\hline & RoTME $(n=55)$ & TaTME $(n=65)$ & $\mathrm{p}$ value \\
\hline Operative time (min) & $247.0 \pm 88.0$ & $297.8 \pm 85.0$ & 0.001 \\
\hline Estimated blood loss (ml) & $38.9 \pm 87.5$ & $113.3 \pm 252.3$ & 0.043 \\
\hline \multicolumn{4}{|l|}{ Procedure } \\
\hline LAR & $48(87.3)$ & $65(100.0)$ & \multirow[t]{2}{*}{0.003} \\
\hline APR & $7(12.7)$ & $0(0.0)$ & \\
\hline Minor complication (Clavien-Dindo 1-2) & $8(14.5)$ & $21(32.3)$ & 0.024 \\
\hline Major complication (Clavien-Dindo $\geq 3$ ) & $5(9.1)$ & $0(0.0)$ & 0.013 \\
\hline Anastomotic leakage & $4(8.3)^{\mathrm{a}}$ & $1(1.5)$ & 0.117 \\
\hline \multicolumn{4}{|l|}{ Resection margin } \\
\hline R0 & $54(98.2)$ & $65(100.0)$ & \multirow[t]{2}{*}{0.275} \\
\hline Aboral R0 & $55(100.0)$ & $65(100.0)$ & \\
\hline Aboral margin (mm) & $27.2 \pm 23.6$ & $10.9 \pm 12.3$ & $<0.001$ \\
\hline CRM R0 & $54(98.2)$ & $65(100.0)$ & 0.275 \\
\hline CRM margin $(\mathrm{mm})$ & $19.0 \pm 15.5$ & $4.2 \pm 1.3$ & $<0.001$ \\
\hline \multicolumn{4}{|l|}{ Quality of mesorectal excision } \\
\hline Grad 1 & $36(90.0)$ & $56(87.5)$ & \multirow[t]{3}{*}{0.333} \\
\hline Grade 2 & $3(7.5)$ & $8(12.5)$ & \\
\hline Grade 3 & $1(2.5)$ & $0(0.0)$ & \\
\hline Length of hospital stay (d) & $8.5 \pm 4.4$ & $7.3 \pm 4.5$ & 0.166 \\
\hline ICU days (d) & $0.7 \pm 0.8$ & $0.2 \pm 0.5$ & 0.001 \\
\hline Readmission (d) & $7(12.7)$ & $3(4.6)$ & 0.109 \\
\hline
\end{tabular}

Numbers indicated as absolute numbers and percentage or mean \pm standard deviation; $p$-values in bold indicate statistical significance between surgical techniques

$A P R$ abdominoperineal rectal resection, $C R M$ circumferential resection margin, $d$ days, $I C U$ intensive care unit, $L A R$ low anterior resection, $\min$ minute, $m l$ milliliter, $n$ number, $p$ p-value, RoTME robotic total mesorectal excision, TaTME transanal total mesorectal excision

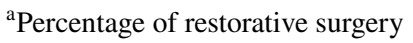


whereas the LARS scores indicated better preservation of anorectal function with RoTME $(\mathrm{p}=0.038)$.

\section{Urinary function}

Both RoTME and TaTME, respectively, led to mild but significant postoperative impairment of male urinary function (IPSS $p=0.013$ vs. $p<0.001$ (Fig. 3); ICIQ-MLUTS $\mathrm{p}=0.032$ vs. $\mathrm{p}<0.001$ (Online Resource Fig. 1)), with postoperative mean values still lying in the top quarter of the respective range. The adjusted analysis of pre- and postoperative score differences revealed significantly lower urinary tract dysfunction in the TaTME group for ICIQ-MLUTS and IPSS score (IPSS RoTME $5.1 \pm 0.9$ vs. TaTME $0.3 \pm 1.0$, $\mathrm{p}<0.001$; ICIQ-MLUTS RoTME $13.8 \pm 4.9$ vs. TaTME $1.8 \pm 5.8, \mathrm{p}=0.038$ (Table 3)).

Female urinary function was also impaired after surgery. According to IPSS, female RoTME patients had preserved function, while TaTME patients revealed significant postoperative deterioration ( $p=0.002$, Fig. 3). Nevertheless, postoperative impairment was again very mild, since the mean values remained in the lower $10-20 \%$ of the score range. Moreover, RoTME patients had a preserved ICIQFLUTS voiding score $(\mathrm{p}=0.480)$, but filling $(\mathrm{p}=0.017)$ and incontinence scores $(p=0.027)$ worsened postoperatively. For TaTME, all ICIQ-FLUTS dimensions were significantly affected $(\mathrm{p}=0.007,0.027$, and 0.041 , respectively; Online Resource Fig. 1). The adjusted analysis revealed no significant differences between techniques for female bladder function (IPSS $p=0.961$; ICIQ-FLUTS $p=0.050,0.185$, and 0.844 , respectively (Table 3 )). Only the ICIQ-FLUTS filling score came close to statistical significance, with a trend in favor of TaTME $(\mathrm{p}=0.050)$.

\section{Sexual function}

Measured by IIEF, male sexual function was slightly impaired after TaTME: erectile function $(p=0.002)$, IIEF final score ( $p=0.003$, Fig. 4), and satisfaction with sexual intercourse ( $p=0.034$, Online Resource Fig. 2) demonstrated significant postoperative impairment. RoTME patients had comparable pre- and postoperative results regarding male sexual function. Overall, after adjustment for confounders, both techniques equally revealed a low impact on male sexual function (Table 3).

Female sexual desire was significantly impaired after TaTME ( $<$ <0.001) (Fig. 5), but the adjusted comparison of individual pre- and postoperative values showed comparable results for RoTME and TaTME in this FSFI dimension. All other FSFI subscores proved equal for both techniques (Online Resource Fig. 3), apart from the pain score, which was significantly lower in the TaTME group ( $\mathrm{p}=0.043$, Table 3$)$.
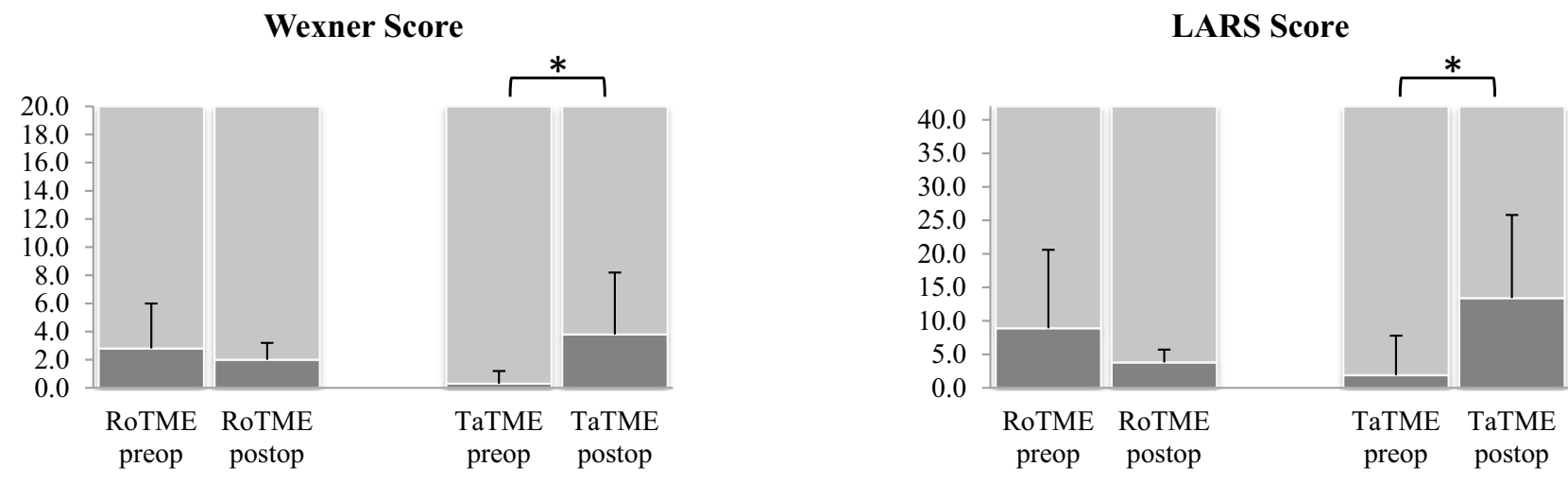

\begin{tabular}{llcccccc}
\hline & \multicolumn{3}{c}{ RoTME } & \multicolumn{3}{c}{ TaTME } & \multicolumn{2}{c}{ Range } \\
& Preop. & Postop. & p-value & Preop. & Postop. & p-value \\
\hline Wexner Score & $2.8 \pm 3.2$ & $2.0 \pm 1.2$ & 0.480 & $0.3 \pm 0.9$ & $3.8 \pm 4.4$ & $<\mathbf{0 . 0 0 1}$ & $0-20$ \\
LARS Score & $8.9 \pm 11.7$ & $3.8 \pm 1.9$ & 0.630 & $1.9 \pm 5.9$ & $13.4 \pm 12.4$ & $<\mathbf{0 . 0 0 1}$ & $0-42$ \\
\hline
\end{tabular}

Fig. 2 Anorectal function results measured by LARS and Wexner score. Favorable results are at the lower end of the scale. Numbers indicated as mean \pm standard deviation; $p$-values in bold indicate statistical significance between surgical techniques and are indicated on the figure as *. LARS, low anterior resection syndrome; RoTME, robotic total mesorectal excision; TaTME, transanal total mesorectal excision 


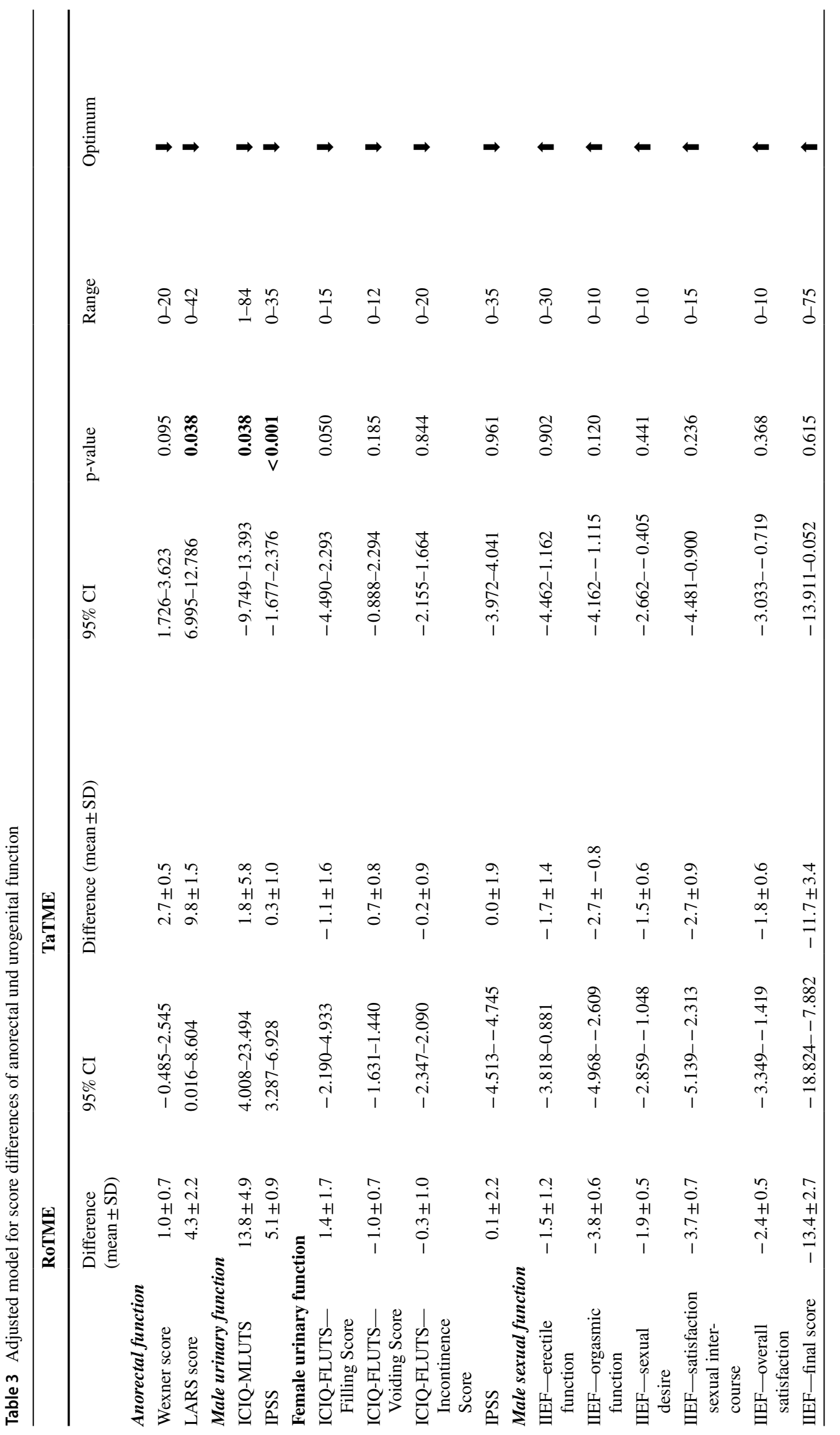




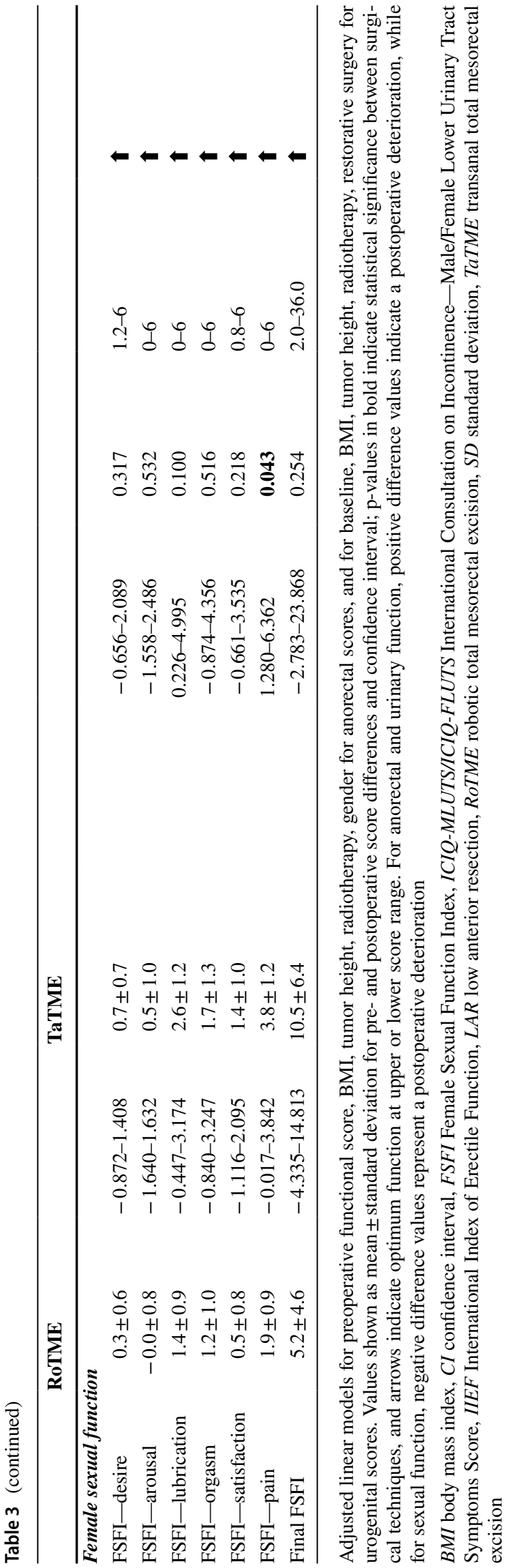

\section{Discussion}

RoTME can preserve anorectal function better than TaTME. In contrast, TaTME is superior regarding male urinary function and may have advantages for female urinary outcomes. For sexual function, comparable results were demonstrated for both techniques; this may result from the multifactorial etiology of sexual dysfunction, on which surgery has the smallest impact [30, 31].

Besides physical affection during surgery, several factors might influence functional outcome after TME. Radiotherapy induces neural damage and thereby impairs bowel function via deterioration of neorectal sensitivity [32]. Moreover, it leads to erectile dysfunction and causes hypogonadism in male and female patients [30,33]. Tumor height also impacts functional outcomes. The further the TME plain has to be dissected towards the pelvic floor, the higher the risk for neural damage. Moreover, gender, and preoperative functional status influence the postoperative anorectal and urogenital outcomes [10, 34]. Hence, postoperative results must be studied in light of these factors. Therefore, we conducted an adjusted linear model, considering all parameters as adjustment factors.

Anorectal dysfunction remains frequent after LAR, with a reported rate of $46.1 \%$ [35] for major LARS using the open approach and increasing after chemoradiation [10]. Likewise, LaTME is associated with major LARS in $29.6-52.0 \%$ of cases [36, 37]. Deterioration of bowel function is caused by damage to the internal anal sphincter, which induces impairment of passive anorectal continence, and the hypogastric plexus.

Our analysis reveals no significant increase compared to the preoperative score for RoTME. In contrast, TaTME patients reported significant postoperative impairment of anorectal function. Nevertheless, worse fecal function was previously shown for TaTME, with major LARS ranging from 33.3 to $59.3 \%$ [6, 36-38], and was inferior to LaTME in direct comparisons in several series [6, 38, 39]. Contributing factors might be lower anastomoses due to technical implications and damage to the internal sphincter by prolonged dilation. Moreover, an elevated risk of entering the extramesorectal plane during the transanal phase may be accountable for a higher proportion of autonomic nerve injuries following TaTME [37]. In our series, after adjustment for confounders (radiation, preoperative anorectal function score, gender, BMI, and tumor height), RoTME resulted in significantly better anorectal function compared to TaTME.

Several non-randomized studies have revealed better urogenital function after RoTME compared to LaTME $[14,40]$, whereas the randomized ROLARR trial showed no difference in bladder or sexual function between LaTME and RoTME [41]. These findings are limited by 


\section{IPSS - male patients}

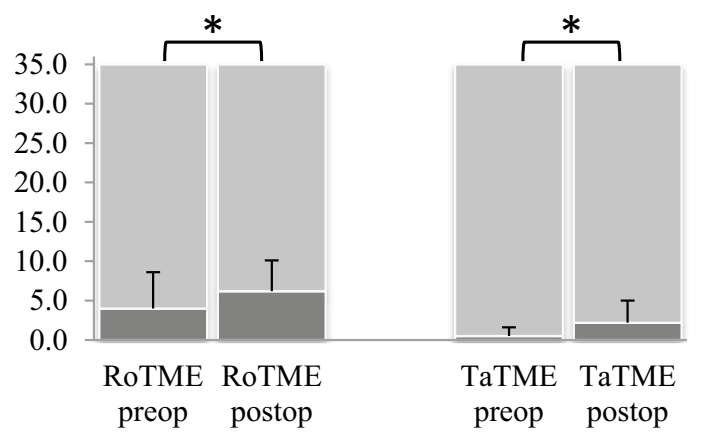

IPSS - female patients

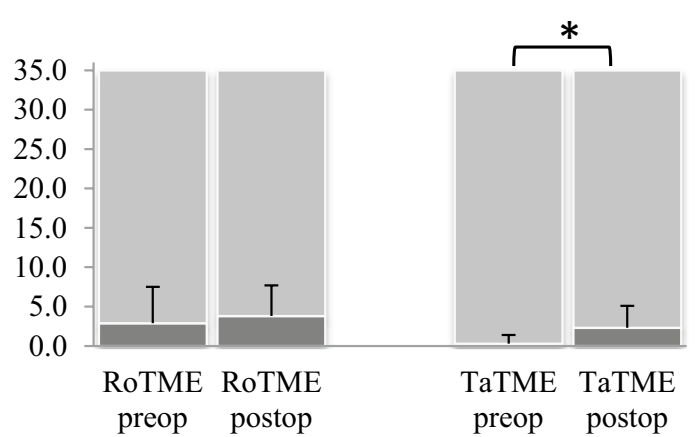

\begin{tabular}{|c|c|c|c|c|c|c|c|}
\hline & \multicolumn{3}{|c|}{ RoTME } & \multicolumn{3}{|c|}{ TaTME } & \multirow[t]{2}{*}{ Range } \\
\hline & Preop. & Postop. & p-value & Preop. & Postop. & p-value & \\
\hline \multicolumn{8}{|l|}{ Male } \\
\hline IPSS & $4.0 \pm 4.6$ & $6.2 \pm 3.9$ & 0.013 & $0.5 \pm 1.1$ & $2.2 \pm 2.8$ & $<0.001$ & $0-35$ \\
\hline \multicolumn{8}{|c|}{ Female } \\
\hline IPSS & $2.9 \pm 2.3$ & $3.8 \pm 2.9$ & 0.079 & $0.3 \pm 0.6$ & $2.3 \pm 2.9$ & 0.002 & $0-35$ \\
\hline
\end{tabular}

Fig. 3 Urinary function measured by IPSS. Favorable results are at the lower end of the scale. Numbers indicated as mean \pm standard deviation; p-values in bold indicate statistical significance between surgical techniques and are indicated on the figure as *. IPSS, Inter-

a short surveillance period of only 6 months and the fact that participating surgeons, while experienced in LaTME, may still have been in their learning curve for RoTME. A recent meta-analysis implied superior urogenital results for

\section{IIEF - Erectile Function}

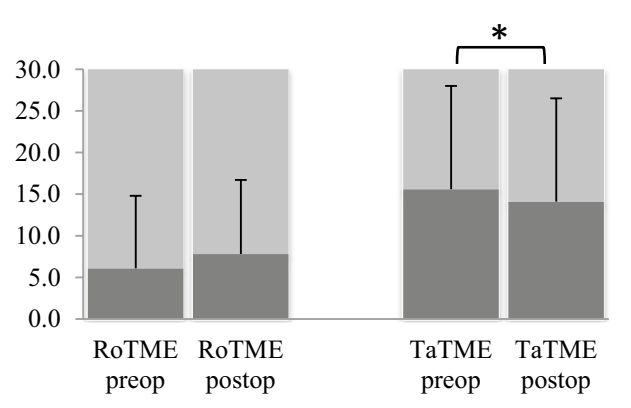

national Prostate Symptom Score; RoTME, robotic total mesorectal excision; SD, standard deviation; TaTME, transanal total mesorectal excision

RoTME over LaTME [34]. Furthermore, TaTME has been shown to provide optimized urinary and male sexual function with greater experience compared to earlier published results [6, 39].

\section{IIEF - Final Score}

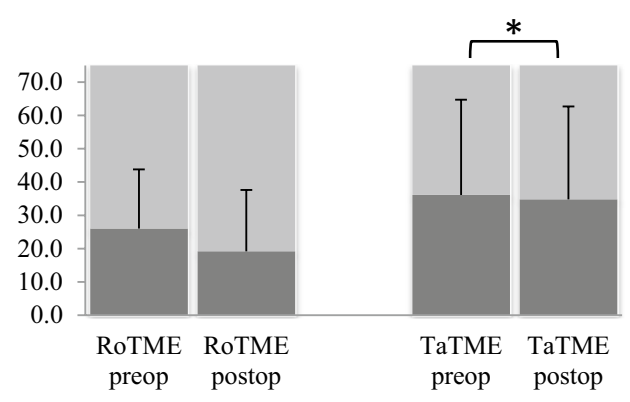

\begin{tabular}{|c|c|c|c|c|c|c|c|}
\hline & \multicolumn{3}{|c|}{ RoTME } & \multicolumn{3}{|c|}{ TaTME } & \multirow[t]{2}{*}{ Range } \\
\hline & Preop. & Postop. & p-value & Preop. & Postop. & p-value & \\
\hline IIEF - Erectile Function & $6.1 \pm 8.7$ & $7.8 \pm 8.9$ & 0.237 & $15.6 \pm 12.4$ & $14.1 \pm 12.4$ & 0.002 & $0-30$ \\
\hline IIEF - Final Score & $26.0 \pm 17.8$ & $19.2 \pm 18.4$ & 0.051 & $36.1 \pm 28.6$ & $34.8 \pm 27.9$ & 0.003 & $5-75$ \\
\hline
\end{tabular}

Fig. 4 Male sexual function measured by IIEF. Favorable results are at the upper end of the scale. Numbers indicated as mean \pm standard deviation; p-values in bold indicate statistical significance between surgical techniques and are indicated on the figure as *. IIEF, International Index of Erectile Function; RoTME, robotic total mesorectal excision; TaTME, transanal total mesorectal excision 


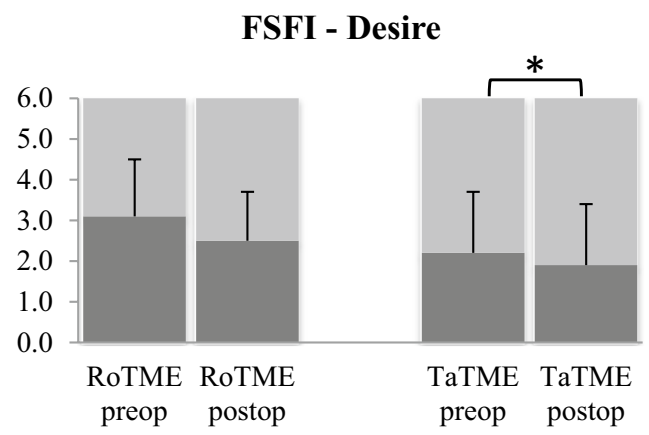

FSFI - Final Score

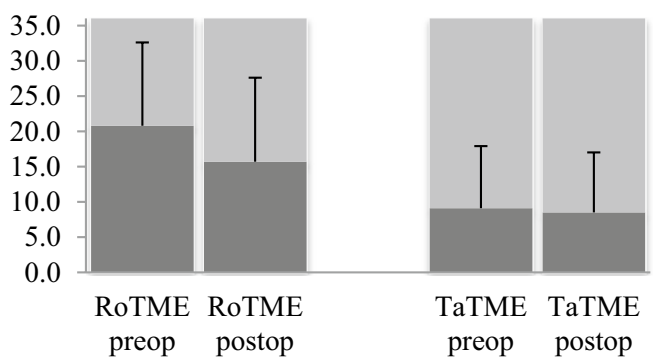

\begin{tabular}{llllllll}
\hline & & RoTME & & & TaTME & \multicolumn{2}{c}{ Range } \\
& Preop. & Postop. & p-value & Preop. & Postop. & p-value \\
\hline FSFI - Desire & $3.1 \pm 1.4$ & $2.5 \pm 1.2$ & 0.292 & $2.2 \pm 1.5$ & $1.9 \pm 1.5$ & $<\mathbf{0 . 0 0 1}$ & $1.2-6$ \\
Final FSFI & $20.8 \pm 11.8$ & $15.7 \pm 11.9$ & 0.477 & $9.1 \pm 8.8$ & $8.5 \pm 8.5$ & 0.483 & $2.0-36.0$ \\
\hline
\end{tabular}

Fig. 5 Female sexual function measured by FSFI. Favorable results are at the upper end of the scale. Numbers indicated as mean \pm standard deviation; $\mathrm{p}$-values in bold indicate statistical significance

Urinary dysfunction is mainly caused by surgical nerve damage [11]. Sympathetic nerve injury induces bladder instability, whereas parasympathetic neural damage triggers detrusor instability [31], causing urge incontinence and voiding dysfunction. Interestingly, evidence on the negative impact of radiation is missing [30]. The IPSS, originally designed for benign prostate hyperplasia [26], is widely accepted for assessing urinary dysfunction in male and female rectal cancer patients, but its application following rectal surgery remains questionable. In contrast, the ICIQ-MLUTS and ICIQ-FLUTS have been developed as universally applicable questionnaires [25]. Male patients experienced a mild, but significant decrease in urinary function in both scores after RoTME and TaTME, in line with the literature $[14,15,37,38]$. Similarly, a significant deterioration of all urinary functional scores was found in female patients. Only female RoTME patients had stable ICIQ-FLUTS voiding scores $(\mathrm{p}=0.480)$. After adjustment for preoperative score values, BMI, radiation, tumor height, and restorative surgery, TaTME demonstrated better urinary results than RoTME for male patients, while female urinary function did not show any difference. Improved exposition of hypogastric nerves might be an advantage of TaTME, leading to superior urinary outcome.

In contrast, sexual dysfunction is a multifactorial issue, which is also influenced by bio-psychological factors such as poor self-image, depression, fatigue, loss of independence, and changes in personal relationships. Surgical aspects in this context include neural damage, cosmetic appearance and stoma fashioning [30, 31]. Currently, male sexual function is between surgical techniques and are indicated on the figure as *. FSFI, Female Sexual Function Index; RoTME, robotic total mesorectal excision; TaTME, transanal total mesorectal excision

comprehensively analyzed and mechanistically understood based on several studies [30,33], whereas female dysfunction is only based on theoretical considerations and underrepresented in literature. On the one hand, sympathetic nerve injury leads to ejaculatory problems in men [31], such as absent, retrograde, or painful ejaculation, and can induce vaginal dryness, diminished inner genital sensation, and orgasm disorders in female patients [30]. On the other, erectile dysfunction [31] due to impairment of vasodilatory function of the erectile tissue and reduced labial swelling [30] are caused by parasympathetic neural damage.

In our series, erectile function $(\mathrm{p}=0.002)$, satisfaction with sexual intercourse $(\mathrm{p}=0.034)$, and IIEF final score $(p=0.003)$ deteriorated significantly after TaTME in male patients, while RoTME led to stable pre- and postoperative IIEF scores. For female patients, sexual desire decreased significantly after TaTME $(\mathrm{p}<0.001)$, but no significant changes were detectable postoperatively in the RoTME group. After adjustment for confounders, male sexual function was comparable between techniques. For female patients, only pain during sexual intercourse was significantly increased for RoTME patients.

\section{Limitations}

RoTME and TaTME were performed in different hospitals by different surgeons. To establish an adequate level of quality, only patients treated after the surgeons had completed the learning curve of at least 40 cases in the respective 
technique were included. Therefore, only one approach was eligible per hospital and surgeon. Nevertheless, this fact might bias the observations. Moreover, age, proportion of neoadjuvant therapy and surgical procedures differed significantly between groups. To balance these effects, score differences were analyzed after adjustment for these confounders. Since patient age is an unspecific risk factor [42], preexisting functional status was recognized by baseline score values. However, this is a limitation of our study.

\section{Conclusion}

Our study represents the first direct functional comparison of RoTME and TaTME and incorporates the largest series of TaTME cases on functional outcome. Overall, RoTME and TaTME resulted in only mild functional impairment after rectal resection. RoTME led to better anorectal results, potentially due to sphincter dilatation or damage of the internal sphincter during TaTME. Meanwhile, there was a noticeably lower rate of severe LARS after both TaTME and RoTME than previously published, despite frequent risk factors such as chemoradiation and low anastomosis. Urinary function benefitted from TaTME in male patients and showed advantages for female patients. Optimized visualization of the hypogastric nerves might support favorable urinary function after TaTME. With surgery having the least impact on sexual function, the results appear comparable for RoTME and TaTME. Our study provides the first evidence of advantages of advanced minimally invasive TME techniques on long-term functional outcomes for rectal cancer patients. Further high-quality analyses are needed to corroborate this observation.

Supplementary Information The online version contains supplementary material available at https://doi.org/10.1007/s00384-021-04030-5.

Acknowledgements Editorial support was provided by Deborah Nock (Medical WriteAway, Norwich, UK), with full review and approval by all authors and funded by Intuitive Surgical Sàrl.

\begin{abstract}
Author contribution All authors contributed to the study conception and design. Material preparation, data collection, and analysis were performed by Julia-Kristin Grass, Roberto Persiani, Flavio Tirelli, Chien-Chih Chen, Marco Caricato, Alice Pecorino, Isabelle J Lang, Marius Kemper, Jakob R Izbicki, Nathaniel Melling, and Daniel Perez. The first draft of the manuscript was written by Julia-Kristin Grass, and all authors commented on previous versions of the manuscript. All authors read and approved the final manuscript.
\end{abstract}

Funding Open Access funding enabled and organized by Projekt DEAL.

Data availability Data are available from the corresponding author upon request.
Code availability Not applicable.

\section{Declarations}

Ethics approval Ethics committee of the general medical council Hamburg (PV5591).

Consent to participate Written and signed informed consent was obtained from all individual participants included in the study.

Consent for publication Patients signed informed consent regarding publishing their data.

Conflict of interest DP is proctor for Intuitive Surgical and has received honoraria. All other authors declare no conflicts of interest.

Open Access This article is licensed under a Creative Commons Attribution 4.0 International License, which permits use, sharing, adaptation, distribution and reproduction in any medium or format, as long as you give appropriate credit to the original author(s) and the source, provide a link to the Creative Commons licence, and indicate if changes were made. The images or other third party material in this article are included in the article's Creative Commons licence, unless indicated otherwise in a credit line to the material. If material is not included in the article's Creative Commons licence and your intended use is not permitted by statutory regulation or exceeds the permitted use, you will need to obtain permission directly from the copyright holder. To view a copy of this licence, visit http://creativecommons.org/licenses/by/4.0/.

\section{References}

1. Kapiteijn E, van de Velde CJ (2002) The role of total mesorectal excision in the management of rectal cancer. Surg Clin North Am 82(5):995-1007

2. Dahlberg M, Pahlman L, Bergstrom R, Glimelius B (1998) Improved survival in patients with rectal cancer: a populationbased register study. Br J Surg 85(4):515-520. https://doi.org/10. 1046/j.1365-2168.1998.00603.x

3. Maurer CA, Z'Graggen K, Renzulli P, Schilling MK, Netzer P, Buchler MW (2001) Total mesorectal excision preserves male genital function compared with conventional rectal cancer surgery. Br J Surg 88(11):1501-1505. https://doi.org/10.1046/j.0007-1323. 2001.01904.X

4. Nesbakken A, Nygaard K, Bull-Njaa T, Carlsen E, Eri LM (2000) Bladder and sexual dysfunction after mesorectal excision for rectal cancer. Br J Surg 87(2):206-210. https://doi.org/10.1046/j. 1365-2168.2000.01357.x

5. Yun JA, Huh JW, Kim HC, Park YA, Cho YB, Yun SH, Lee WY, Chun HK (2016) Local recurrence after curative resection for rectal carcinoma: the role of surgical resection. Medicine (Baltimore) 95(27):e3942. https://doi.org/10.1097/MD.0000000000003942

6. Koedam TW, van Ramshorst GH, Deijen CL, Elfrink AK, Meijerink WJ, Bonjer HJ, Sietses C, Tuynman JB (2017) Transanal total mesorectal excision (TaTME) for rectal cancer: effects on patient-reported quality of life and functional outcome. Tech Coloproctol 21(1):25-33. https://doi.org/10.1007/ s10151-016-1570-z

7. Clausen N, Wolloscheck T, Konerding MA (2008) How to optimize autonomic nerve preservation in total mesorectal excision: clinical topography and morphology of pelvic nerves and 
fasciae. World J Surg 32(8):1768-1775. https://doi.org/10.1007/ s00268-008-9625-6

8. Maurer CA, Renzulli P, Kull C, Kaser SA, Mazzucchelli L, Ulrich A, Buchler MW (2011) The impact of the introduction of total mesorectal excision on local recurrence rate and survival in rectal cancer: long-term results. Ann Surg Oncol 18(7):1899-1906. https://doi.org/10.1245/s10434-011-1571-0

9. Bryant CL, Lunniss PJ, Knowles CH, Thaha MA, Chan CL (2012) Anterior resection syndrome. Lancet Oncol 13(9):e403-408. https://doi.org/10.1016/S1470-2045(12)70236-X

10. Emmertsen KJ, Laurberg S, Rectal Cancer Function Study G (2013) Impact of bowel dysfunction on quality of life after sphincter-preserving resection for rectal cancer. Br J Surg 100 (10):1377-1387. https://doi.org/10.1002/bjs.9223

11. Lange MM, Maas CP, Marijnen CA, Wiggers T, Rutten HJ, Kranenbarg EK, van de Velde CJ, Cooperative Clinical Investigators of the Dutch Total Mesorectal Excision T (2008) Urinary dysfunction after rectal cancer treatment is mainly caused by surgery. Br J Surg 95 (8):1020-1028. https://doi.org/10.1002/bjs.6126

12. Lange MM, Marijnen CA, Maas CP, Putter H, Rutten HJ, Stiggelbout AM, Meershoek-Klein Kranenbarg E, van de Velde CJ, Cooperative clinical investigators of the D (2009) Risk factors for sexual dysfunction after rectal cancer treatment. Eur J Cancer 45 (9):1578-1588. https://doi.org/10.1016/j.ejca.2008.12.014

13. Soreide K, Soreide AH (2013) Using patient-reported outcome measures for improved decision-making in patients with gastrointestinal cancer - the last clinical frontier in surgical oncology? Front Oncol 3:157. https://doi.org/10.3389/fonc.2013.00157

14. Luca F, Valvo M, Ghezzi TL, Zuccaro M, Cenciarelli S, Trovato C, Sonzogni A, Biffi R (2013) Impact of robotic surgery on sexual and urinary functions after fully robotic nerve-sparing total mesorectal excision for rectal cancer. Ann Surg 257(4):672-678. https://doi. org/10.1097/SLA.0b013e318269d03b

15. Kim HJ, Choi GS, Park JS, Park SY, Yang CS, Lee HJ (2018) The impact of robotic surgery on quality of life, urinary and sexual function following total mesorectal excision for rectal cancer: a propensity score-matched analysis with laparoscopic surgery. Colorectal Dis 20(5):O103-O113. https://doi.org/10.1111/codi. 14051

16. Quah HM, Jayne DG, Eu KW, Seow-Choen F (2002) Bladder and sexual dysfunction following laparoscopically assisted and conventional open mesorectal resection for cancer. Br J Surg 89(12):1551-1556. https://doi.org/10.1046/j.1365-2168.2002. 02275.x

17. Jayne DG, Brown JM, Thorpe H, Walker J, Quirke P, Guillou PJ (2005) Bladder and sexual function following resection for rectal cancer in a randomized clinical trial of laparoscopic versus open technique. Br J Surg 92(9):1124-1132. https://doi.org/10.1002/ bjs. 4989

18. Asoglu O, Matlim T, Karanlik H, Atar M, Muslumanoglu M, Kapran Y, Igci A, Ozmen V, Kecer M, Parlak M (2009) Impact of laparoscopic surgery on bladder and sexual function after total mesorectal excision for rectal cancer. Surg Endosc 23(2):296-303. https://doi.org/10.1007/s00464-008-9870-7

19. Breukink SO, van der Zaag-Loonen HJ, Bouma EM, Pierie JP, Hoff C, Wiggers T, Meijerink WJ (2007) Prospective evaluation of quality of life and sexual functioning after laparoscopic total mesorectal excision. Dis Colon Rectum 50(2):147-155. https:// doi.org/10.1007/s10350-006-0791-z

20. Amin MB, Greene FL, Edge SB, Compton CC, Gershenwald JE, Brookland RK, Meyer L, Gress DM, Byrd DR, Winchester DP (2017) The Eighth Edition AJCC Cancer Staging Manual: continuing to build a bridge from a population-based to a more "personalized" approach to cancer staging. CA: a Cancer Journal for Clinicians 67 (2):93-99
21. Dindo D, Demartines N, Clavien PA (2004) Classification of surgical complications: a new proposal with evaluation in a cohort of 6336 patients and results of a survey. Ann Surg 240(2):205-213. https://doi.org/10.1097/01.sla.0000133083.54934.ae

22. Rahbari NN, Weitz J, Hohenberger W, Heald RJ, Moran B, Ulrich A, Holm T, Wong WD, Tiret E, Moriya Y, Laurberg S, den Dulk M, van de Velde C, Buchler MW (2010) Definition and grading of anastomotic leakage following anterior resection of the rectum: a proposal by the International Study Group of Rectal Cancer. Surgery 147(3):339-351. https://doi.org/10.1016/j.surg.2009.10.012

23. Jorge JM, Wexner SD (1993) Etiology and management of fecal incontinence. Dis Colon Rectum 36(1):77-97. https://doi.org/10. 1007/bf02050307

24. Emmertsen KJ, Laurberg S (2012) Low anterior resection syndrome score: development and validation of a symptom-based scoring system for bowel dysfunction after low anterior resection for rectal cancer. Ann Surg 255(5):922-928. https://doi.org/10. 1097/SLA.0b013e31824f1c21

25. Abrams P, Avery K, Gardener N, Donovan J, Board IA (2006) The International Consultation on Incontinence Modular Questionnaire: www.iciq.net. J Urol 175 (3 Pt 1):1063-1066; discussion 1066. https://doi.org/10.1016/S0022-5347(05)00348-4

26. Barry MJ, Fowler FJ, Jr., O'Leary MP, Bruskewitz RC, Holtgrewe HL, Mebust WK, Cockett AT (1992) The American Urological Association symptom index for benign prostatic hyperplasia. The Measurement Committee of the American Urological Association. J Urol 148 (5):1549-1557; discussion 1564. https://doi.org/10. 1016/s0022-5347(17)36966-5

27. Rosen RC, Riley A, Wagner G, Osterloh IH, Kirkpatrick J, Mishra A (1997) The international index of erectile function (IIEF): a multidimensional scale for assessment of erectile dysfunction. Urology 49(6):822-830. https://doi.org/10.1016/s0090-4295(97) 00238-0

28. Rosen R, Brown C, Heiman J, Leiblum S, Meston C, Shabsigh R, Ferguson D, D'Agostino R Jr (2000) The Female Sexual Function Index (FSFI): a multidimensional self-report instrument for the assessment of female sexual function. J Sex Marital Ther 26(2):191-208. https://doi.org/10.1080/009262300278597

29. Perez D, Melling N, Biebl M, Reeh M, Baukloh JK, Miro J, Polonski A, Izbicki JR, Knoll B, Pratschke J, Aigner F (2018) Robotic low anterior resection versus transanal total mesorectal excision in rectal cancer: a comparison of 115 cases. Eur J Surg Oncol 44(2):237-242. https://doi.org/10.1016/j.ejso.2017.11.011

30. Lange MM, van de Velde CJ (2011) Urinary and sexual dysfunction after rectal cancer treatment. Nat Rev Urol 8(1):51-57. https://doi.org/10.1038/nrurol.2010.206

31. Lim RS, Yang TX, Chua TC (2014) Postoperative bladder and sexual function in patients undergoing surgery for rectal cancer: a systematic review and meta-analysis of laparoscopic versus open resection of rectal cancer. Tech Coloproctol 18(11):993-1002. https://doi.org/10.1007/s10151-014-1189-x

32. Sturiale A, Martellucci J, Zurli L, Vaccaro C, Brusciano L, Limongelli P, Docimo L, Valeri A (2017) Long-term functional follow-up after anterior rectal resection for cancer. Int J Colorectal Dis 32(1):83-88. https://doi.org/10.1007/s00384-016-2659-6

33. Bruheim K, Guren MG, Dahl AA, Skovlund E, Balteskard L, Carlsen E, Fossa SD, Tveit KM (2010) Sexual function in males after radiotherapy for rectal cancer. Int J Radiat Oncol Biol Phys 76(4):1012-1017. https://doi.org/10.1016/j.ijrobp.2009.03.075

34. Kowalewski KF, Seifert L, Ali S, Schmidt MW, Seide S, Haney C, Tapking C, Shamiyeh A, Kulu Y, Hackert T, Muller-Stich BP, Nickel F (2020) Functional outcomes after laparoscopic versus robotic-assisted rectal resection: a systematic review and meta-analysis. Surg Endosc. https://doi.org/10.1007/ s00464-019-07361-1 
35. Grass JK, Chen CC, Melling N, Lingala B, Kemper M, Scognamiglio P, Persiani R, Tirelli F, Caricato M, Capolupo GT, Izbicki JR, Perez DR (2021) Robotic rectal resection preserves anorectal function: systematic review and meta-analysis. Int J Med Robot:e2329. https://doi.org/10.1002/rcs.2329

36. Rubinkiewicz M, Zarzycki P, Witowski J, Pisarska M, Gajewska N, Torbicz G, Nowakowski M, Major P, Budzynski A, Pedziwiatr M (2019) Functional outcomes after resections for low rectal tumors: comparison of Transanal with laparoscopic Total Mesorectal excision. BMC Surg 19(1):79. https://doi.org/10.1186/ s12893-019-0550-4

37. Veltcamp Helbach M, Koedam TWA, Knol JJ, Velthuis S, Bonjer HJ, Tuynman JB, Sietses C (2019) Quality of life after rectal cancer surgery: differences between laparoscopic and transanal total mesorectal excision. Surg Endosc 33(1):79-87. https://doi.org/10. 1007/s00464-018-6276-Z

38. Bjoern MX, Nielsen S, Perdawood SK (2019) Quality of life after surgery for rectal cancer: a comparison of functional outcomes after transanal and laparoscopic approaches. J Gastrointest Surg 23.https://doi.org/10.1007/s11605-018-4057-6

39. Keller DS, Reali C, Spinelli A, Penna M, Di Candido F, Cunningham C, Hompes R (2019) Patient-reported functional and quality-of-life outcomes after transanal total mesorectal excision. Br J Surg 106(4):364 366. https://doi.org/10.1002/bjs.11069
40. Kim JY, Kim NK, Lee KY, Hur H, Min BS, Kim JH (2012) A comparative study of voiding and sexual function after total mesorectal excision with autonomic nerve preservation for rectal cancer: laparoscopic versus robotic surgery. Ann Surg Oncol 19(8):2485-2493. https://doi.org/10.1245/s10434-012-2262-1

41. Jayne D, Pigazzi A, Marshall H, Croft J, Corrigan N, Copeland J, Quirke P, West N, Rautio T, Thomassen N, Tilney H, Gudgeon M, Bianchi PP, Edlin R, Hulme C, Brown J (2017) Effect of roboticassisted vs conventional laparoscopic surgery on risk of conversion to open laparotomy among patients undergoing resection for rectal cancer: the ROLARR Randomized Clinical Trial. JAMA 318(16):1569-1580. https://doi.org/10.1001/jama.2017.7219

42. Kupsch J, Jackisch T, Matzel KE, Zimmer J, Schreiber A, Sims A, Witzigmann H, Stelzner S (2018) Outcome of bowel function following anterior resection for rectal cancer-an analysis using the low anterior resection syndrome (LARS) score. Int J Colorectal Dis 33(6):787-798. https://doi.org/10.1007/s00384-018-3006-x

Publisher's Note Springer Nature remains neutral with regard to jurisdictional claims in published maps and institutional affiliations. 